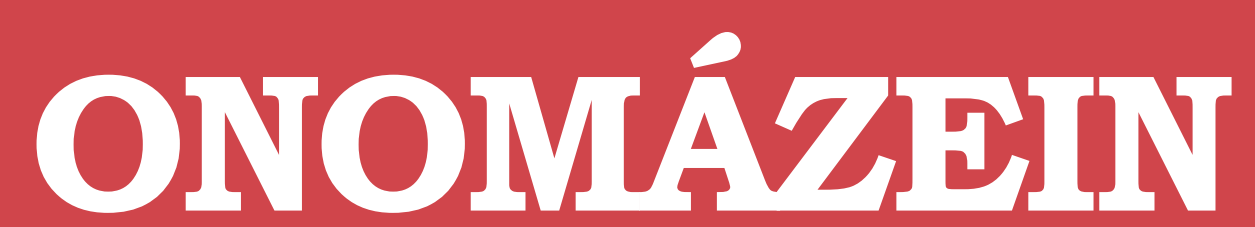

Revista semestral de lingüística, filología y traducción
PONTIFICIA UNIVERSIDAD

\title{
Rasgos históricos de lengua y errores en la interpretación y lectura de las fuentes coloniales: reino, país, provincia, nación ${ }^{1}$
}

Historical language characteristics and mistakes in the interpretation and reading of colonial sources: kingdom, country, province, nation.

\section{Raïssa Kordić Riquelme}

Universidad de Chile

Chile

\section{(c) $(i)$}

Raïssa Kordić: Departamento de Lingüística, Universidad de Chile, Chile.

| Correo electrónico: raissa.kordic@gmail.com 


\section{Resumen}

La lectura manuscrita de fuentes documentales históricas y literarias chilenas presenta desafíos de alta complejidad, tanto en el aspecto de la transcripción misma como también en la interpretación semántico-léxica de sus textos. Pareciera que historiadores y estudiosos de la literatura (co-
Ionial y moderna) ignoraran que se trata no solo de letras viejas - más o menos antiguas-, sino que de un estado de lengua histórico determinado, que plantea, como en cualquier ámbito de la investigación científica, conocimientos específicos especializados.

Palabras clave: Filología chilena; Filología hispanoamericana; Crítica textual; Paleografía.

\section{Abstract}

The reading of Chilean historical and literary manuscripts presents high complexity challenges coming from the handwriting as well as the semantic and lexical interpretation of the texts. It seems that historians and scholars of both Colonial and Modern
Literature do not know that those documents are not only ancient, but that they represent a determine moment in the history of the language. Consequently, having specific training is needed like in any other scientific research.

Keywords: Chilean Philology; Hispano-American Philology; Text Criticism; Paleography 
El ejercicio académico de la Filología, por su naturaleza interdisciplinaria, requiere de la discusión y de la reflexión entre especialistas de distintas áreas. Requiere de manera especial del cultivo de la vieja práctica del compartir.

En un artículo de hace unos años atrás, en el suplemento Artes y Letras (Kordic, R., "Chile colonial. Filología e historia: Las cartas de sor Dolores Peña y Lillo". Artes y Letras, El Mercurio, domingo 3 de junio de 2007), enumeré unos errores muy ilustrativos cometidos por José Toribio Medina en su edición de La Guerra de Chile (de 1888), señalando, además, que si los filólogos nos dedicáramos a historiadores por simple afición cometeríamos los mismos errores que los historiadores cometen al dedicarse por mera afición a transcribir manuscritos y editar textos.

Entre los ejemplos citados, mencioné cómo Medina transformaba, por su errada lectura, por su lectura no técnica, al capitán Guirao en el capitán Quirós; al mapuche Caniancura, en Camaricura; la "chicharra no callada" aparecía en su edición como "la cristiana no callada"; la "punición del pueblo castellano" (el "castigo a los españoles') lo convertía en la "permisión del pueblo castellano", induciendo a una interpretación exactamente opuesta; Aipiñande se transformaba en Aypirián; una expresión ecuestre como "dar de puntapiés al aguijada" se convierte en un inverosímil "dar de puntapiés a la quijada" (es decir, el jinete enviando patadas hacia el hocico del caballo); el nombre de Juan Fernández es simplemente confundido con el de Juan Sánchez; el "ciego Polifemo" es transformado en el "nuevo Polifemo", y un personaje tan clásico de la mitología como Hipermenestra (o Hipermnestra, la mayor de las danaides, hija del Rey de Argos), Io transformaba Medina en "por ministra". Debemos reconocer que estos ejemplos no son poca cosa y que las conclusiones extraíbles para la Historiografía chilena pueden ser enormes, si es que no dramáticas.
La intención y naturaleza de mis críticas, que afortunadamente una mayoría del público académico sí entendió positivamente, fue la de hacer un muy comprometido aporte a los estudios humanísticos chilenos, invitando a esmerarse por superar lo que uno identifica como falencia y aportar la pequeña parcela, el pedazo, que corresponde al conocimiento de la propia especialidad.

Por alguna curiosa razón, que me cuesta entender, los chilenos nos percibimos a nosotros mismos como muy destacados en el concierto mundial en casi todas las materias. Pero basta con asomarse a los congresos internacionales para apreciar que, si bien nuestras escuelas son muy buenas, se requiere de la autocrítica y de la autosuperación. Como decía mi amiga Celestina hace unos cinco siglos, "más vale el áspero consejo que la blanda lisonja”.

Personalmente, he intentado poner en práctica y divulgar esta actitud una y otra vez, por ejemplo en las clases de Paleografía que hago en la Universidad de Chile para los estudiantes de Historia. Es decir, he intentado hacer el esfuerzo de enseñar a superar estas falencias en las lecturas de los textos de época a las mismas personas que he criticado. Una búsqueda, al menos un intento, de coherencia y de complementación académica.

No puedo dejar de mencionar, en esta experiencia de compartir con las otras disciplinas, el debate un poco más personal y tan enriquecedor con los amigos historiadores, como, por ejemplo, Emma De Ramón o Sergio Villalobos. Con Villalobos, a pesar de nuestras profundas diferencias valóricas y de cosmovisión, compartimos un impulso, una actitud frente al problema del conocimiento que para mí, al menos, es fundamental. Se genera en el diálogo (a veces verdaderas peleas) una diversión en su recto sentido, que no es superficial, sino esa diversión profunda que al alejar, al distraer de los problemas y pesares, tiene la virtud de generar felicidad en la vida. La diversión del ser y del conocer. 
Recordemos el uso de divertir en nuestros textos chilenos antiguos: el autor de Cautiverio feliz señala en medio de su congoja que se va al río a divertir sus cuidados: es decir, a distraer, a alejar sus cuitas y sus dolores. A esa diversión me refiero. Debo agregar que nos hacíamos consultas mutuas permanentemente y me agradaban mucho sus llamadas un día domingo a las nueve de la mañana, para discutir o enrostrarme algo que había publicado en un suplemento del día.

El decir lo que realmente se piensa no es costumbre nacional y por supuesto puede ser mal recibido, pero lo que yo valoro en esto es el intento de buscar la honestidad científica y hacer más ligero y alegre el día a día. La mística de compartir, dialogar y discutir y criticar en su más puro sentido es en sí misma un impulso de la vida.

\section{Algunos ejemplos}

Agregaré acá algunos ejemplos, sintetizados, de problemas de interpretación lingüística histórica y filológica de obras fundamentales para la historiografía. Varias de estas voces han sido erróneamente interpretadas en la exégesis historiográfica nacional.

La comprensión literaria e historiográfica del discurso está en importante medida determinada por el conocimiento conceptual y referencial que tengamos de la lengua de los textos estudiados: de allí la importancia de la interpretación filológica realizada por el editor al establecer un texto crítico.

Si bien muchos de los textos chilenos coloniales han sido aprovechados por los humanistas sin hermenéuticas filológicas de por medio, y sin correcciones de tradicionales lecturas erradas, cualquier interpretación que se precie de sutil y rigurosa requiere, naturalmente, eliminar ambigüedades y descansar en la certeza del texto y de su contenido.

Desde el punto de vista semántico, las palabras nunca actúan solas, no existen solas: actúan y existen en campos léxicos, en grupos interrelacionados de voces en que cada lengua particular organiza sus significados de manera distinta y, por supuesto, en contextos determinados.

Las palabras república, nación, país, provincia tuvieron durante la colonia americana usos parcial y circunstancialmente equivalentes, pero también muy diferenciables.

\section{Nación}

(primeros testimonios, c. 1495) nación de gentes, 'estirpe, prole, linaje' (lat. natio, 'Nación', 'diosa del nacimiento').

\section{fr. origine.}

(Covarrubias, 1611.), "reino o provincia estendida”. (1734 Aut.), nación, "el acto de nacer”, "Iugar de nacimiento".- Ser ciego de nación.

En la Crónica de Vivar hallamos: "Todas Ias naciones de los indios", para hablar de todos los grupos étnicos (c. XIX). Ocurrencia única en la Crónica.

En las Cartas de Valdivia hay dos ocurrencias: "ha treinta años que peleo con diversas naciones e gente", "he peleado contra muchas naciones". Siempre muy vinculado al sentido de pertenencia nativa y de orígenes.

A través de toda la documentación hispanoamericana de época, y hasta el siglo XIX, corroboramos el valor sémico de la palabra naciones -es decir, cuando es usada en plural- como equivalente de 'etnias', 'culturas originarias', 'nativos', sin el valor político-administrativo que

2 Núñez de Pineda, F., Cautiverio feliz, RIL - Consejo del libro y la lectura, Santiago de Chile, 2001, edición crítica de Mario Ferreccio y Raïssa Kordic. 
posteriormente adquirió, a partir de la Ilustración; son conceptos que por supuesto tardaron en divulgarse en estas lejanas tierras, entre otras cosas, por la llegada tan tardía de la imprenta y de la educación pública.

En Chile, durante las primeras décadas de siglo XIX, encontramos ambos significados en pleno uso y vigencia. Veamos, a continuación, este ejemplo de ambos usos en un mismo contexto, aludiendo, con la voz en singular, a la administración político-cultural chilena y, por otra parte, con la voz en plural, a la población mapuche como tales nativos de ese suelo, y no, lamento en el alma decirlo, como reconocimiento a un estado político-administrativo independiente, como algunos han querido interpretar (ciencia es ciencia, aunque a veces duela):

[...] he acordado a nombre de la Nación Chilena fijar por bases preliminares los artículos siguientes: habrá una paz eterna y duradera entre este Gobierno y sus súbditos con todas las Naciones que habitan desde la otra banda del Bíobío hasta los confines de la tierra. (Decreto de 1817, firmado por Bernardo O’Higgins).

República (lat. res publica, 'los asuntos de interés públicos, el estado, la administración del estado').

El sentido más frecuente de la expresión es "asuntos de estado", "actividades que afectan al conjunto de la población”, también "bienestar que ofrece el estado", "el estado", etc.

En algunos pocos casos, sin embargo, tiene específicamente el valor de "un estado en el cual participan los ciudadanos, un "estado libre", opuesto a tiranía, y se lo usa principalmente para aludir al período histórico pre-imperial romano, es decir, el período anterior a la insurrección de Julio César, con la que comienza el principado o imperio (año 44 A. C). Este valor específico está documentado por primera vez en Cicerón (siglo I A. C.) y Tácito (siglo I D. C.), no antes. La voz es exclusivamente latina y no traduce ninguna expresión griega específica. Esto, por supuesto, no significa que Platón y Aristóteles no hablaron de "democracia"; esta sí es palabra griega, y la encontramos ya en Tucídides (siglo V A. C.).

República ya circulaba en América para el siglo XVI, pero no la hallamos ni en Vivar ni en Valdivia, y la registra el CORDE (Corpus Diacrónico del Español) para Chile desde 1569: "malos tratamientos y necesidades que padecen los soldados que ayudan a sustentar la tierra y causa para que haya alguna alteración en la república” (Carta de fray Juan de Torralba, en De Granda, RAE, 1993), pero con ínfima frecuencia de uso (un caso hasta 1700).

En México, 20 casos para la misma época: "conservación de la república", "no se le siga daño a la república”, "escándalo de la república”.

En Perú hay 8 casos. "la república de los ingas", "el gobierno de la república”. Un interesante ejemplo: "[decía] en un antiguo oráculo que aquellos Incas tenian, que pasados tantos reyes habían de ir gentes estrañas y nunca vistas y quitarles el reino y destruir su república y idolatria” (Anello, 1895).

Se la entiende como un 'gobierno central que incluye numerosos estados'. 'Modelo de orden moral'. "Vivían en sus pueblos en modo de república, con toda pulicía”. "La república de la dicha ciudad" (nótese el claro uso exclusivamente relativo a orden moral o administrativo de una entidad geográfica menor y dependiente).

En 1737, Autoridades la define como "el gobierno del público, de muchos... a diferencia del monárquico", "por extensión se llama también a algunos pueblos".

Testimoniado en Perú en 1569 también como 'orden ético del gobierno'. México: 1525 encontramos: "capitanes de la república”, que ya se acerca al uso nuevo, 'república o comunidad', pero teniendo también muy presente la noción de 'orden'. En Chile es el mismo uso, pero hay 
solo 2 ocurrencias hasta 1600. En los virreinatos es muy frecuente. Tarda más en expandirse por chile.

\section{Provincia (=zona)}

Del lat. (pro cul vincta) provincia, 'radio de acción, misión, comisión, función', en 1611 (Covarrubias.) Para los romanos eran las regiones conquistadas fuera de Italia.

En Vivar: "las provincias de Chile", "la provincia de los incas", "provincia de Atacama", "esta provincia, o, por mejor decir, desierto", "en toda la tierra y provincias de Indias", "provincia de Mapocho", "provincia de la ciudad de Valdivia", etc. Su uso en la Crónica es abundantísimo, y hace referencia general a zonas pertenecientes al reino o que pretendían serlo (se hablaba "salir hacia una provincia" aun no conquistada). Hay usos similares en las Cartas de Valdivia.

Reino (regnum, 'autoridad o poder regio', 'monarquía, poder absoluto, soberanía, dominio, imperio').

En español antiguo (medieval y algunas ocurrencias hasta siglo XVI) regno, que no está en América.

En Autoridades (1737): "una o muchas provincias sujetas a un rey".

En Terreros (1788), "país que está sujeto al gobierno de un rey o monarca”.

Los usos en América colonial designan de manera un tanto imprecisa una determinada extensión territorial; bastante parecida a región, pero en la que se ejerce un evidente dominio político.

(Región 'gran extensión de tierra, habitada por muchos pueblos de una misma nación... y por lo regular obedece a un rey o príncipe' - regio, regionis, en Nebrija, 1492, es sinónimo de reinado, pues tienen la misma raíz etimológica, aunque después perdió esa connotación-).
Recuérdese que los dos virreinatos iniciales y más antiguos del siglo XVI fueron el de Nueva España y Perú, y los dos nuevos del siglo XVIII, Santa Fe y el Río de la Plata. Las capitanías generales de Guatemala, Cuba, Venezuela, Chile, y Filipinas tuvieron una vida prácticamente independiente de los virreinatos y mucha dificultad para integrar sus zonas regionales, salvo quizá Cuba.

La expresión "reino de Chile", que hasta hoy confunde al menos a los estudiantes de historia, fue una denominación de índole geográfica muy ambigua. Desde la época de Felipe II, la documentación pública y privada y las leyes de Indias designaron usualmente a Chile de esta manera.

En los primeros años, la zona fue designada como "Nueva Extremadura" o "provincia de Nueva Extremadura", nombre otorgado por Pedro de Valdivia y mantenido hasta la muerte de Jerónimo de Alderete. Posteriormente, se utilizaron otras denominaciones, no oficiales y menos extendidas, tales como "Flandes Indiano".

A la denominación de Reino de Chile (llamado gobernación —desde 1541 hasta 1778 como dependiente del virreinato peruano- y luego capitanía general, autónoma del virreinato) se le han dado explicaciones populares como aquella de que cuando Felipe II casó con María Tudor era todavía príncipe, y su padre, el emperador Carlos V, lo nombró "rey de Chile" para darle el mismo estatus que la reina. Esto, precisamente, porque jamás tuvo el rango oficial de virreinato. El uso de reino estuvo en definitiva vinculado a denominaciones administrativas, militares o geográficas poco precisas, pero claramente no aludieron históricamente nunca a la condición de reino o virreinato, en el sentido administrativo o político.

La voz aparece desde los primeros documentos en Chile (desde 1547): "reino y gobernación del Nuevo Extremo" en carta de Valdivia de 1548.

"En este reino y provincias de la Nueva Extremadura” (1549 Docs. inéditos de Medina). 
"Reino de Chile" aparece en CORDE solo desde 1614 (desengaño y reparo de González Nájera), "reino y provincias".

Vivar: "gobernación y reino", "reinos y tierras", "gobernación y reino de Chile". Es interesante el caso: "la navegación de los reinos de Chile [...] para venir a los del Pirú es a popa” (cap. LXXII), que reflejaría que tampoco se usaba el uso extensivamente, es decir, hablar de reino para Chile por conformar parte del virreinato peruano, por ejemplo: un uso así se descarta.

Tengamos presente que para Román ( $M a-$ nuel Antonio, el mejor registro de usos chilenos de época), en reino (en el DRAE) "falta [...] campo, terreno, casa de uno", que se usa también en plural "Viene esta acepción desde el tiempo de Virgilio, por lo menos".

Por esta misma causa, en territorio boliviano (Charcas) se le llama "Reino" a una provincia, en varios documentos de la época (en CORDE) escritos en ese mismo territorio:

La fama de la gran riqueza del Perú a los que acá estamos nos parece que lo devimos de soñar $y$, en despertando, no vimos nada. Crea Vuestra Magestad que no es la veytena parte de lo que allá se dize: no ay dos vezinos en esta cibdad, ni en la de Arequipa, que no deban la renta de quatro años, o tres por lo menos, de sus repartimientos y encomiendas, y en Lima, lo mesmo. En el Cuzco avrá cinco o seys encomenderos ricos, los demás todos son pobres, excepto los que dellos tratan y son mercaderes, que éstos tienen todo el dinero; y los vezinos y soldados (que así se llaman acá los que no tienen repartimientos de yndios) que algo tienen, están en Lima negociando que les den más, y por dinero piensan alcançarlo, que sus ovras no an merecido: los que menos an seruido a Vuestra Magestad en este reino están allá pretendiendo mercedes (1562, Licenciado Matienço, Súplica para ser designado corregidor).

Y porque más claramente vea Vuestra Magestad la nesçesidad qu'este reino tiene de que rresida en esta çiudad desta Audiençia e que ella tenga el gouierno para dar horden en las cosas e des- asosiegos que cada día subçeden, para que con mas breuedad se pueda rremediar sin yr a buscar el rremedio tan lejos como es a la Ciudad de los Reyes (1566-1569, carta anónima sobre el alzamiento de los chiriguanaes).

Tal como para Bolivia, la referencia de reino para Chile se extendió de manera bastante imprecisa (que ya su tradición lingüística lo era) y con connotaciones más claramente administrativas y geográficas, parecida a región, pero en la que se ejerce un evidente dominio político. Este uso de reino fue reafirmado con el ejercicio de los scriptoria de conquista chilenos, donde unas fuentes se basaban normalmente en otras producidas por un pequeño grupo de individuos en contacto y se reproducían sin mayor cuestionamiento, como es normal, usos lingüísticos y expresivos de toda índole ("Scriptorium de conquista...", prólogo a Cartas de relación, Ferreccio, M., 1992).

País. Equivalente en lat. a regio, terra, ‘territorio’. Derivados: paisano, 'aldeano'.

En Autoridades "región, reino, provincia o territorio". Ni en Valdivia ni en Vivar está presente. Primera ocurrencia registrada: Arauco domado (Oña, 1596) describiendo costumbres mapuches: "por ser en su país, mi patria amada" (único caso CORDE hasta 1600 en Chile).

En México también encontramos un solo caso: "el estado del país antes de la conquista" (Diego de Landa, Los mayas de Yucatán, s. XVI, español con treinta años de permanencia en México). Ninguno en Perú. Muy asociado al lugar físico y sus márgenes administrativos y/o de propiedad política. Recuérdese el valor sémico vigente hasta hoy en italiano de paese, voz cognada y hermana de nuestro país, y con un valor sémico similar al perdido en lengua española: 'territorio cultivado y habitado', zona, lugar.

Si cotejamos estas palabras brevemente analizadas con las voces equivalentes en otras lenguas románicas, cuyo origen y significados 
compartimos en algún momento histórico, veremos que muchas de ellas sobreviven y su significado era o ha sido el mismo.

\section{La literatura}

Con respecto a la relación con los literatos, los estudiosos de la literatura, debo recordar que nuestra escuela filológica chilena es más lingüística que literaria.

La producción chilena, el objeto de estudio filológico chileno de época (no el moderno) pertenece a una tradición textual manuscrita y de un solo testimonio, a diferencia de la impresa y de múltiples testimonios, como es la virreinal americana (México, Perú) y también la española.

El hecho de haber tenido estas zonas virreinales imprenta ya en el siglo XVI y universidades que dictaban carreras liberales también en ese mismo siglo, marca una diferencia gigantesca en cuanto al objeto de estudio para la crítica textual desde los puntos de vista estilístico y lingüístico, y por tanto -y esto es fundamental- marca una diferencia en cuanto al método de trabajo exigido para abordar el objeto de estudio. Nosotros en Chile no tuvimos modelos literarios realmente divulgados en la población sino hasta el siglo XIX, con la educación pública y el funcionamiento de la imprenta como objeto cultural en ese mismo siglo; no antes.

Los modelos de lengua virreinales-peninsulares no llegaron a imponerse de forma clara y masiva en Chile sino con la Independencia. Ello repercute en hechos tan simples pero determinantes como el que los textos de la Colonia chilena, sin excepción, carecen, por ejemplo, de una puntuación orgánica. La que se usa es caótica y caprichosa, no sistemática y, por tanto, carente de significado; la lengua misma tiene un perfil notablemente más rústico y arcaizante en todos sus niveles. Es decir, nuestra lengua en el Chile del siglo XVI se asemeja mucho más a la peninsular de la época, pero en los albores de la Independencia (por ejemplo, en los textos de Sor Dolores
Peña y Lillo) y poco después, nos encontramos con rastros de una lengua ya diferenciada del modelo peninsular, muy chilenizada, que escandalizó a Andrés Bello y que lo llevó a escribir sus Advertencias para padres de familia y maestros de escuela, por el temor a la fragmentación lingüística, por el temor a que esas diferencias que habían ido pronunciándose durante el transcurso de la Colonia acabaran por consolidarse en una lengua distinta a la española.

Es, paradójicamente, la Independencia la que permite la divulgación y enseñanza de la lengua española peninsular, culta y canónica, por las necesidades de comunicación y organización de las repúblicas, y nos aleja del modelo local más arcaizante y diferenciador. Nos independizamos para ser por derecho americanos, pero nuestro lenguaje, para que fuera funcional y pudiera enseñarse masivamente, adoptó el modelo central.

Por esa razón, nuestra escuela filológica, desde los inicios, ha debido preocuparse de la lengua y no de la literatura, porque la lengua era lengua de Capitanía general, no de virreinato; era una lengua con características muy particulares, con conservación abundante de rasgos vulgares, algunos de muy baja ocurrencia y casi ignorados en las gramáticas históricas de la lengua. Es normal encontrar en los textos chilenos de la Colonia, especialmente en los escritos por criollos chilenos, fenómenos de lengua apenas descritos y escasamente testimoniados en la lengua peninsular o en la virreinal, pero tan recurrentes en Sor Dolores (Epistolario), como la -s epentética ultracorrecta, en las voces juesves, destesto, caminesmos, manisfestado, o la nasal epentética, en voces como sumanmente, juengan (por juegan), parensen ('parecen'), sengún, hanbrán, y tantas otras; o voces cuyos valores sémicos o cuya morfología no está en registros léxicos de lengua española: precausar ('precaver'), residio ('residuo'), etc.

La literatura moderna chilena no ha sido críticamente editada (nuestros premios nobe- 
les, para empezar). Ellos requieren de un trabajo evidentemente de índole más literaria y ecdótica que lingüística, por las mismas razones antes señaladas.

La realización de ediciones filológicas en Chile se plantea como un atractivo pero desamparado campo de acción, que lo sitúa en la práctica, a estas alturas, más bien como una pasión, en su recto y etimológico sentido. En distintas escuelas universitarias se están realizando ediciones denominadas "críticas" de obras chilenas de siglo XIX y XX, pero por lo general son realizadas sin ningún conocimiento técnico científico, ni tampoco son producto de la formación en alguna escuela especializada, sino solo balbuceadas y engendradas a partir de manuales de culturas extranjeras y de buenas intenciones sin oficio.

Quizá el mayor problema de la Filología como práctica investigativa en nuestro país está en el escasísimo conocimiento que se tiene de ella, de su utilidad, de su clarividencia. Se la confunde muy frecuentemente con la actividad editora-impresora, es decir, con el oficio de hacer o rehacer ediciones sin aporte científico de suyo. Por eso la divulgación y explicación de su función e importancia cultural son indispensables.

Es tarea pendiente de la Filología chilena la divulgación de nuestras obras en los congresos de la especialidad: Ios americanistas, estudiosos norteamericanos, españoles, e incluso latinoamericanos prefieren dedicarse a los textos de México o Perú, quizá también Colombia, porque tienen un mayor interés literario, por su cultura estilística virreinal. Debemos tener presente que, de entre las zonas periféricas coloniales, Chile tiene la producción textual más abundante y destacada (a diferencia de Argentina, que, estando en una situación cultural comparable en la época, prácticamente no cuenta con producción colonial).

Recordemos, para terminar, que historiadores, filólogos, lingüistas y literatos, somos esen- cialmente complementarios y debemos aunar esfuerzos por dignificar los estudios humanísticos chilenos.

Ser complementarios significa tener la honestidad científica de no hacer aquello para lo que no se está preparado y, por otra parte, de acercarse al otro en busca de esta complementación de especialidades.

La Filología chilena, tan brillantemente impulsada e iniciada científicamente por Mario Ferreccio en nuestro país, solo podrá fortalecerse en el contexto de una cooperación académica orientada por objetivos y por actitudes tolerantes y generosas.

\section{Bibliografía citada}

Anello. Juan Anello Oliva: Historia del reino y provincias del Perú, 1631, en Pazos Varela, Lima, 1895.

Autoridades. Real Academia Española: Diccionario de Autoridades (1726-1730), Madrid: Gredos, 1964.

Cautiverio feliz. Cautiverio feliz y razón individual de las guerras dilatadas del reino de Chile, Francisco Núñez de Pineda, edición crítica de Mario Ferreccio y Raïssa Kordić, estudio preliminar de Cedomil Golć, RIL, 2001.

CORDE, Corpus diacrónico del español [www.rae.es].

Covarrubias. S. de Covarrubias: Tesoro de la lengua castellana o española (1611), Madrid: Horta, 1943 (varias posteriores).

Crónica. Crónica y relación copiosa y verdadera, de Jerónimo de VIVAR. Cito por mi edición en preparación. V., también, edición de Leopoldo SaezGodor, Berlín: Colloquium-Verlag, 1979.

Cartas Valdivia. Cartas de relación, Pedro de VALDivia, edición crítica de Mario Ferreccio, Santiago: Universitaria, varias ediciones desde 1970. 
DRAE. Real Academia Española: Diccionario de la lengua española, Madrid, 2001.

FerReCCIO, M.: El epistolario cronístico valdiviano y el scriptorium de conquista, estudio preliminary edición crítica de la Cartas de relación de Pedro de Valdivia, Barcelona: Lumen, 1991.

Kordić, R.: "Chile colonial. Filología e historia: Las cartas de sor Dolores Peña y Lillo", suplemento Artes y Letras, El Mercurio, domingo 3 de junio de 2007.

La Guerra de Chile, autor anónimo (s. XVII), edición crítica de Mario Ferreccio y Raïssa Kordić, estudios preliminares de Osvaldo Sılva y José Miguel Barros, Santiago: Universidad de Chile, Consejo del libro y la Lectura, BACh 4, 1997. 